\title{
Feasibility of an Armature-Reaction-Compensated Permanent-Magnet Synchronous Generator in Island Operation
}

\author{
Katteden Kamiev, Janne Nerg, Senior Member, IEEE, Juha Pyrhönen, Member, IEEE, \\ Valeriy Zaboin, and Juan Tapia, Member, IEEE
}

\begin{abstract}
Armature-reaction-compensated permanent-magnet synchronous generators are a particular type of hybrid excitation synchronous generators, where the main flux is created by the permanent magnets and the field winding is needed only to compensate the armature reaction. This paper studies the feasibility of an armature-reaction-compensated permanent magnet synchronous generator in island operation by comparison with a conventional electrically excited synchronous generator and permanent magnet synchronous generator. The aim of this paper is to demonstrate the performance of an armature-reaction-compensated permanent magnet synchronous generator and its operation principle in island operation. As part of the study, a $55 \mathrm{~kW}$ prototype was built and tested. The experimental results of the prototype are presented.
\end{abstract}

Index Terms-Armature-reaction-compensated permanentmagnet synchronous generator (ARC-PMSG), hybrid excitation synchronous machine (HESM), island operation, permanentmagnet synchronous machine, synchronous machine.

\section{NOMENCLATURE}

$a \quad$ Number of parallel paths.

$B_{\delta} \quad$ Air gap flux density.

$D_{\text {out }}$ Stator outer diameter.

$D_{\mathrm{r}} \quad$ Rotor outer diameter.

$D_{s} \quad$ Air gap diameter.

$C_{\text {fuel }}$ Fuel price.

$C_{\text {gen }}$ Generator price and its maintenance.

$E_{0} \quad$ No-load induced phase voltage.

$E_{f} \quad$ Field winding emf.

$f$ Frequency.

$h_{\mathrm{PM}}$ Permanent-magnet (PM) height.

$I_{f} \quad$ Excitation current.

$I_{d} \quad$ Stator current along direct axis.

$I_{q} \quad$ Stator current along quadrature axis.

Manuscript received January 28, 2013; revised August 12, 2013; accepted October 4, 2013. Date of publication November 8, 2013; date of current version March 21, 2014.

K. Kamiev, J. Nerg, and J. Pyrhönen are with the Department of Electrical Engineering, LUT Energy, Lappeenranta University of Technology, 53851 Lappeenranta, Finland (e-mail: katteden.kamiev@lut.fi; janne.nerg@lut.fi; juha.pyrhonen@lut.fi).

V. Zaboin is with the Department of Electrical Machines, Saint-Petersburg State Polytechnical University, 195251 Saint-Petersburg, Russia (e-mail: zabv@ @rambler.ru).

J. Tapia is with the Department of Electrical Engineering, University of Concepcion, Concepcion 3349001, Chile (e-mail: juantapia@udec.cl).

Color versions of one or more of the figures in this paper are available online at http://ieeexplore.ieee.org.

Digital Object Identifier 10.1109/TIE.2013.2289871

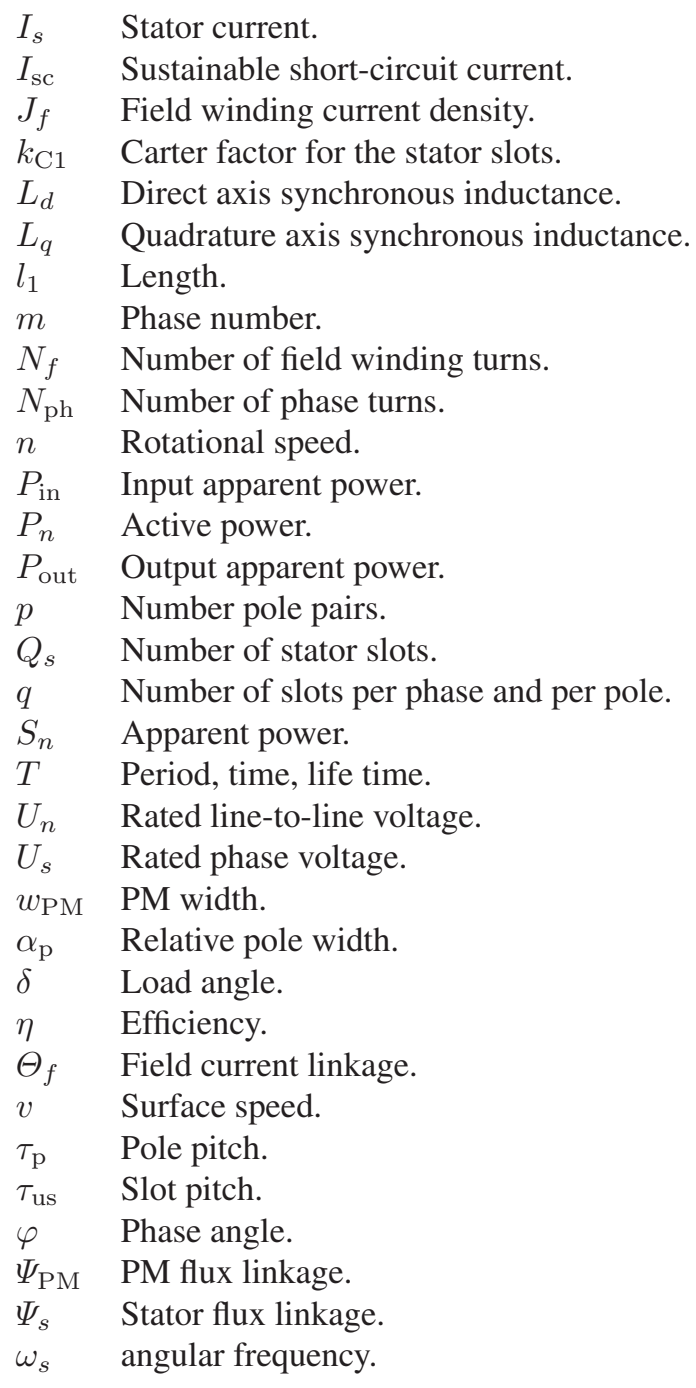

\section{INTRODUCTION}

$\mathbf{O}$ NE OF the most important factors for the customers while buying a synchronous generator (SG) is the price of the electricity produced by a generator during its life time $T$. More simply, the electricity price can be expressed as

$$
\begin{aligned}
\text { Electricity price }\left[\frac{€}{\mathrm{kWh}}\right] & =\frac{C_{\text {gen }}[€]+C_{\text {fuel }}[€]}{T[\mathrm{~h}] P_{\text {in }}} \\
& =\frac{C_{\text {gen }}[€]+C_{\text {fuel }}[€]}{\frac{T[\mathrm{~h}] P_{\text {out }}}{\eta}}
\end{aligned}
$$


where $C_{\text {gen }}$ is the generator price and its maintenance, $C_{\text {fuel }}$ is the price of the fuel (diesel, coal, gas, or water), $P_{\text {gen }}$ is the generator output power, and $\eta$ is the efficiency of the generator.

As can be seen in (1), the main factors which influence on the electricity price are: 1) fuel price; 2) generator reliability; 3) generator mass and dimensions; and 5) generator efficiency.

The last three items refer to the generator performance while the fuel price depends on the amount of mineral products which steadily decrease in the Earth. The generator reliability during its operation and generator mass and dimensions determine $C_{\text {gen }}$ in (1) that is the initial cost of the machine.

Generally, to increase the reliability and efficiency of a generator, and hence to decrease the electricity price, it is necessary to increase the mass and dimensions of the machine. For the customers using generators in network operations, for example in power plants, could still put up with the increasing masses and dimensions. However, in the case of island operation, for example in ships, the size and weight of the generator are important and sometimes represent paramount importance. Furthermore, one additional challenge comes from the fact that generators in island operation must fulfill the requirements given by classification societies.

Despite the mutual contradictory tendencies, that is to increase the efficiency and reduce the weight and size of generators, the researches are trying to find compromise solutions, as well to carry out the mutual fulfillment of both these trends in the design of electrical machines by studying alternative technologies. One of these technologies represents hybrid excitation synchronous generators (HESGs).

HESGs attract the researches more and more. In the literature, such machines are referred to by a number of different names, the most common being "a hybrid excitation synchronous machine" (HESM) [1]-[7], "a double excitation synchronous machine" (DESM) [8]-[12], and "a permanentmagnet assisted synchronous generator" [13], [14]. Some comprehensive reviews of such machines are provided for example in [15]-[17].

In HESGs, the total current linkage is produced by the simultaneous action of two different rotor excitation sources: a permanent magnet (PM) excitation and an electrical excitation. The target behind the use of these two excitation sources is to combine the advantages of permanent magnet synchronous generators (PMSGs) and conventional electrically excited synchronous generators (EESGs). PMs produce the main excitation flux while the excitation winding mainly takes care of the armature reaction compensation. Because of this action there is no significant need to try to control the air gap flux of an HESG after the correct design of the PM excitation. Thanks to PMs, the electrical excitation losses are much lower than those of SMs with conventional electrical excitation. If the PM excitation is arranged so that the machine can run without significant field winding current at its typical partial load, the machine efficiency approximately corresponds to the efficiency of a PM-excited machine.

In view of the key function of the field winding in the machine discussed in this paper, the term "armaturereaction-compensated permanent magnet synchronous generator" (ARC-PMSG) is used here.
TABLE I

MAIN BOUNDARY CONDITIONS FOR AN SG FOR AC ISLAND OPERATION

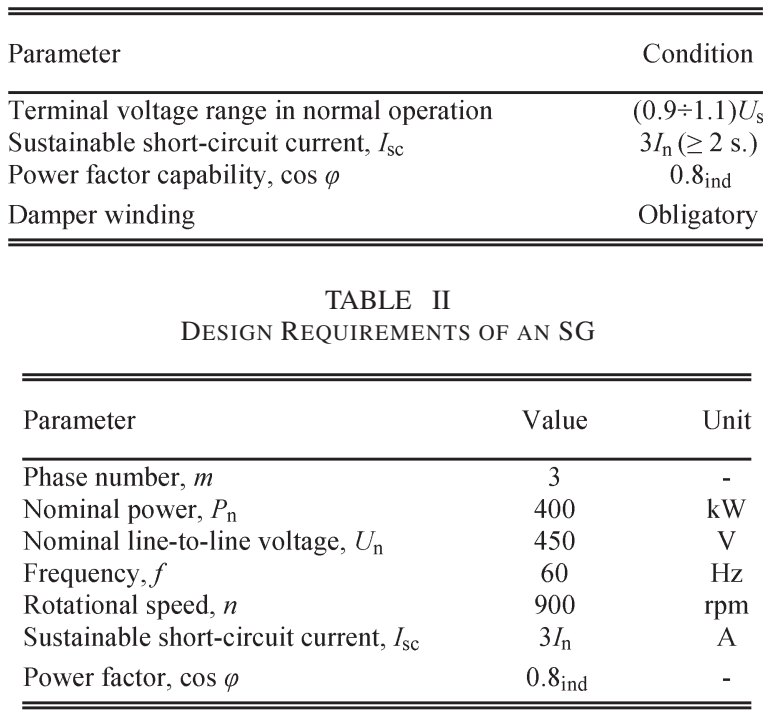

HESGs for island operation were studied in previous works [18], [19]. In earlier work [18], one asymmetrical and two symmetrical possible topologies were considered. Since the symmetrical topologies showed better performance than the asymmetrical one, they were chosen in [19] for comparison with a conventional EESG. This paper extends previous work [19] by presenting a detailed analysis of the ARC-PMSG based on FEA and experimental results.

This paper studies the applicability of an ARC-PMSG to a marine diesel genset. This is the main reason why the analysis is done in island operation. The contribution of the paper is to propose a solution where an ARC-PMSG replaces an SG for instance in ship electrical power generation while meeting all the requirements for SMs given by classification societies, particularly as regards island operation.

The aim of this paper is to present the performance of an ARC-PMSG by comparison with the EESG and PMSG in island operation, report a prototype of the ARC-PMSG, and demonstrate the experimental results. In fact, the PMSG is quickly eliminated in the paper for the considered application. The comparison is finally between the ARC-PMSG and the EESG.

The performance of the studied SGs in island operation is studied by the two-dimensional (2-D) finite element analysis (FEA), and their comparison is performed. As part of the study, a $55 \mathrm{~kW}$ prototype of the ARC-PMSG was built to permit evaluation of the predicted results.

\section{SGS FOR ISLAND OPERATION}

The main boundary conditions set for an SG in island operation determined in [15] are given in Table I. Table II presents the design requirements of a low-power SG based on Table I.

Fig. 1 illustrates a phasor diagram of a salient pole SG that meets all the aforementioned boundary conditions. Let us next investigate the phasor diagram in more detail. It must be kept in mind that the following analysis is done utilizing normalized that is per unit values. In the rated operation when the rated 


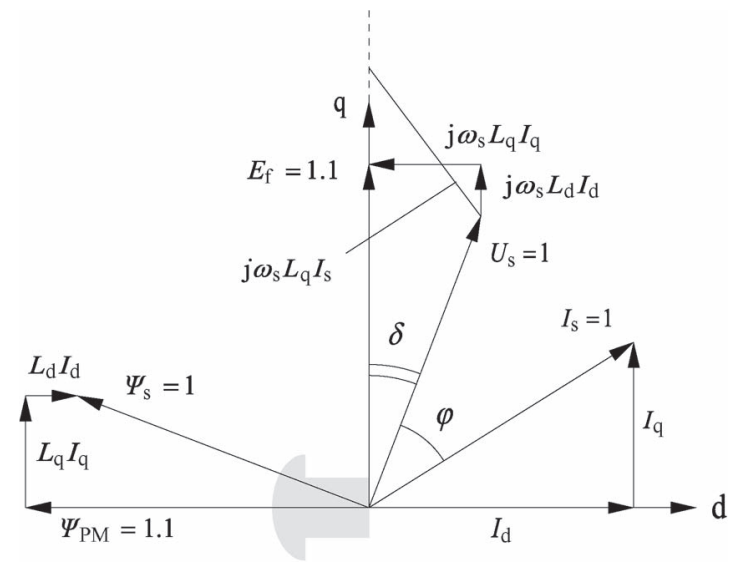

Fig. 1. Phasor diagram of a salient pole SG that meets all the main boundary conditions set. $L_{d}=0.2$ p.u. and $L_{q}=0.68$ p.u. in the diagram. The power $S=1$ p.u. and the phase voltage $U_{s}=1$ p.u. are set to their rated values.

speed is $n=1$ p.u. and hence the angular frequency is $\omega_{s}=$ 1 p.u., the rated phase voltage is $U_{s}=1$ p.u., the rated current is $I_{s}=1$ p.u., and the field winding emf is $E_{f}=1.1$ p.u.

According to the phasor diagram, it is possible to write the following equations:

$$
\begin{aligned}
U_{s} \cos \delta+\omega_{s} L_{d} I_{d} & =E_{f} \\
U_{s} \sin \delta & =\omega_{s} L_{q} I_{q}
\end{aligned}
$$

where $I_{d}$ and $I_{q}$, the stator current components, can be expressed as

$$
\begin{aligned}
& I_{d}=I_{s} \sin (\delta+\varphi) \\
& I_{q}=I_{s} \cos (\delta+\varphi) .
\end{aligned}
$$

Inserting (4) and (5) into (2) and (3), respectively, it is possible to solve the synchronous inductances $L_{d}, L_{q}$ as functions of the load angle $\delta$ and the power factor angle $\varphi$

$$
\begin{aligned}
L_{d} & =\frac{E_{f}-U_{s} \cos \delta}{\omega_{s} I_{s} \sin (\delta+\varphi)} \\
L_{q} & =\frac{U_{s} \sin \delta}{\omega_{s} I_{s} \cos (\delta+\varphi)} .
\end{aligned}
$$

As can be seen in (6) and (7), only the d-axis synchronous inductance $L_{d}$ value depends on the emf $E_{f}$. If the sustainable short-circuit current is three times the rated current, the maximum allowable $L_{d}$ in p.u. in an SG is

$$
L_{\mathrm{d} \max }=\frac{E_{f}}{\omega_{s} I_{\mathrm{sc}}}=\frac{1.1}{3}=0.37 \text {. }
$$

Fig. 2 presents the behavior of the synchronous inductances $L_{d}, L_{q}$ as a function of load angle at $E_{f}=1.1$ p.u., $E_{f}=$ 1.3 p.u., $E_{f}=1.5$ p.u. and $\cos \varphi=0.8_{\text {ind }}$. The ratio of the synchronous inductances $L_{q} / L_{d}$ as a function of load angle at $E_{f}=1.1$ p.u. and $\cos \varphi=0.8_{\text {ind }}$ is shown in Fig. 3 .

As can be seen in Fig. 2, when $L_{d}=L_{q}$, an SG becomes a nonsalient pole machine, and the synchronous inductance $L_{d}=$ $L_{q}=L_{s}$ is equal to 0.15 p.u. when the load angle is $\delta=6.6^{\circ}$. When $L_{d}<L_{q}$, an SG is only a pure PMSG. In the case when

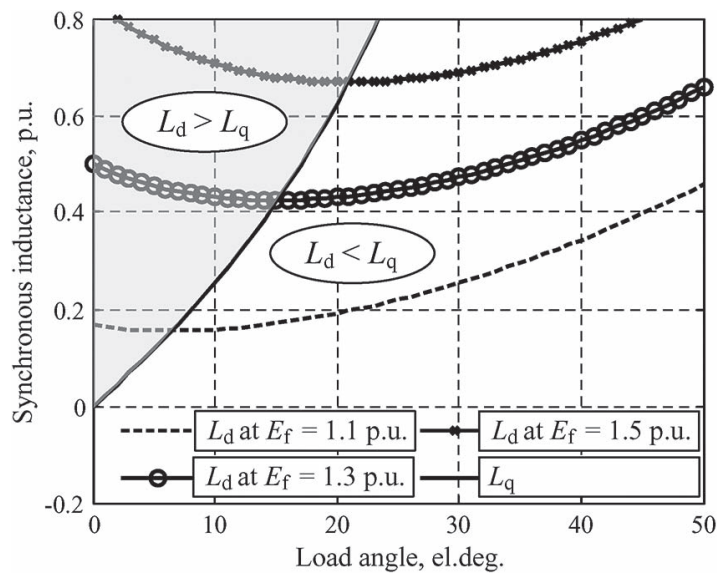

Fig. 2. Synchronous inductances $L_{d}, L_{q}$ as a function of the load angle at $\cos \varphi=0.8_{\text {ind }}, S=1$ p.u., and $U_{s}=1$ p.u.

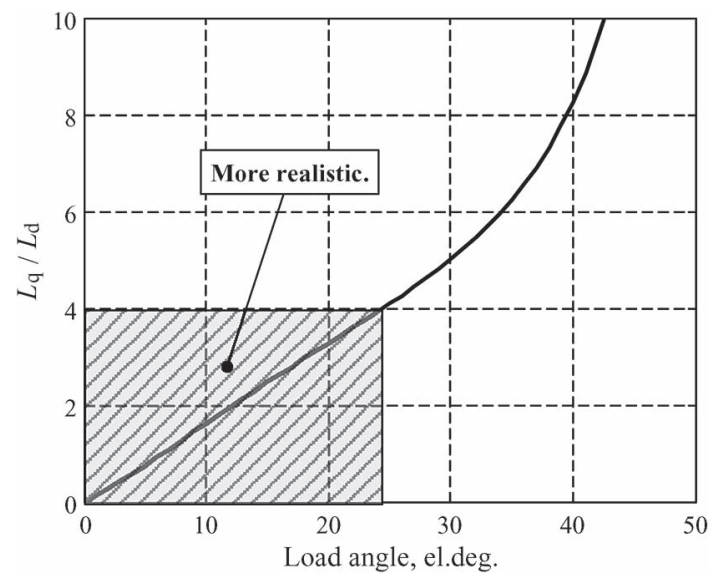

Fig. 3. Synchronous inductance ratio $L_{q} / L_{d}$ as a function of the load angle $\delta$ at $E_{f}=1.1$ p.u., $\cos \varphi=0.8_{\text {ind }}, S=1$ p.u., and $U_{s}=1$ p.u.

$L_{d}>L_{q}$, an SG can be either a conventional EESG or pure PMSG [20].

According to Fig. 3, in the required boundary conditions $E_{f}=1.1$ p.u., $\cos \varphi=0.8_{\text {ind }}, L_{d}=0.37$ p.u., $S=1$ p.u., and $U_{s}=1$ p.u., the ratio $L_{q} / L_{d}$ is more than 10 , which is difficult to deliver in a pure PMSG. The ratio $L_{q} / L_{d} \leq 4$ seems more realistic, and therefore, reaching acceptable values of $L_{q}$ is possible only when $L_{d} \leq 0.22$ p.u. The values determined for $L_{d}$ are low even for a pure PMSG, and thus result in a large machine. This is due to the fact that the d-axis synchronous inductance is inversely proportional to the machine dimensions while the synchronous leakage inductance $L_{\mathrm{s} \sigma}$ has a relatively low value [18]. It can be concluded that a pure PMSG for island operation is overdimensioned, and hence, economically inefficient. Therefore, a pure direct-on-line PMSG is not suitable for island operation.

Another important conclusion is that by varying the emf of the excitation, see Fig. 2, it is possible to fulfill the desired boundary conditions with the acceptable synchronous inductances of an SG. The variation of the induced voltage is possible by applying an electrical excitation which exists in conventional EESGs and HESGs. Moreover, since the considered application belongs to the constant speed application, because of $f=$ const, and the voltage must be nearly constant at different 
TABLE III

Main GeOMEtry Data of SGs With Different Excitations

\begin{tabular}{|c|c|c|c|}
\hline Parameter & EESG & $\begin{array}{c}\text { ARC- } \\
\text { PMSG } \\
\text { with SCL }\end{array}$ & $\begin{array}{c}\text { ARC- } \\
\text { PMSG } \\
\text { with ACL }\end{array}$ \\
\hline Stator outer diameter, $D_{\text {sout }}$ & $1015 \mathrm{~mm}$ & $1015 \mathrm{~mm}$ & $1015 \mathrm{~mm}$ \\
\hline Air gap diameter, $D_{\mathrm{s}}$ & $730 \mathrm{~mm}$ & $730 \mathrm{~mm}$ & $730 \mathrm{~mm}$ \\
\hline Active length, $l_{1}$ & $512 \mathrm{~mm}$ & $476 \mathrm{~mm}$ & $446 \mathrm{~mm}$ \\
\hline Air gap length, $\delta$ & $5 \mathrm{~mm}$ & $5 \mathrm{~mm}$ & $5 \mathrm{~mm}$ \\
\hline Stator slot opening, $b_{1}$ & $18.5 \mathrm{~mm}$ & $18.5 \mathrm{~mm}$ & $18.5 \mathrm{~mm}$ \\
\hline Stator slot total height, $h_{1}$ & $79.4 \mathrm{~mm}$ & $79.4 \mathrm{~mm}$ & $79.4 \mathrm{~mm}$ \\
\hline Number stator slots, $Q_{\mathrm{s}}$ & 48 & 48 & 48 \\
\hline $\begin{array}{l}\text { Number of slots per phase and } \\
\text { per pole, } q\end{array}$ & 2 & 2 & 2 \\
\hline $\begin{array}{l}\text { Number of conductors in a } \\
\text { slot, } z_{\mathrm{Q}}\end{array}$ & 8 & 8 & 8 \\
\hline Number of phase turns, $N_{\mathrm{ph}}$ & 16 & 16 & 16 \\
\hline $\begin{array}{l}\text { Number of field winding turns } \\
\text { per pole, } N_{\mathrm{f}}\end{array}$ & 44 & 27 & 44 \\
\hline Field winding pole width & $210 \mathrm{~mm}$ & $210 \mathrm{~mm}$ & $210 \mathrm{~mm}$ \\
\hline $\begin{array}{l}\text { Filed winding conductor } \\
\text { dimensions }\end{array}$ & $\begin{array}{c}2.1 \times 22 \\
\mathrm{~mm}^{2}\end{array}$ & $\begin{array}{c}2.1 \times 22 \\
\mathrm{~mm}^{2}\end{array}$ & $\begin{array}{c}2.1 \times 22 \\
\mathrm{~mm}^{2}\end{array}$ \\
\hline PM dimensions, $h_{\mathrm{PM}} \times w_{\mathrm{PM}}$ & - & $\begin{array}{c}25 \times 203, \\
\mathrm{~mm}^{2}\end{array}$ & $\begin{array}{c}25 \times 150, \\
\mathrm{~mm}^{2}\end{array}$ \\
\hline Rated excitation current, $I_{\mathrm{f}}$ & $153 \mathrm{~A}$ & $124.6 \mathrm{~A}$ & $124.6 \mathrm{~A}$ \\
\hline
\end{tabular}

loads, the electrical excitation is needed mainly to compensate the armature reaction to keep the air gap flux density nearly constant.

\section{SGs With DifFERENT EXCITATIONS}

This section considers the SGs with different excitations that is the conventional EESG and two proposed HESGs which were designed according to the requirements given in Table II. The direct-on-line PMSG was not designed because it is not suitable for island operation. Table III provides the main geometry data of the designed SGs with different excitations.

\section{A. Conventional EESG}

Fig. 4(a) illustrates the cross-sectional view of the EESG which satisfies the design requirements presented in Table II. The conventional EESG was designed according to [21], [22]. The laminated stator of the SG is made of M600-50A. The material of the laminated rotor iron poles is $\mathrm{Fe} 52$ and the material of the solid rotor yoke is Fe52C.

\section{B. Proposed HESGs}

In the family of SMs, HESMs can be placed between separately magnetized SMs and PMSMs. HESMs can be classified according to the magnetic flux paths due to PMs and field windings [2]: series HESMs and parallel HESMs. In series HESMs, the PMs and field windings are connected in series: the flux due to the excitation coils pass through the PMs, see Fig. 5(a). In parallel HESMs, the trajectory of the PM flux differs from the flux produced by the excitation coil, see Fig. 5(b).

Series HESMs have been criticized for the fact that the field winding has to excite the machine through the PM poles, which is considered a drawback [11]. However, the issue is not at all straightforward. By comparing series and parallel HESMs,

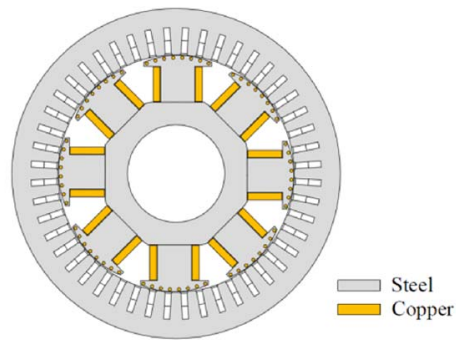

(a)

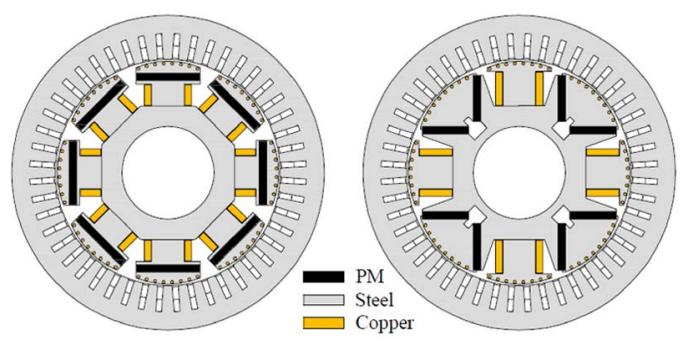

(b)

(c)

Fig. 4. Cross-sectional views of the designed SGs with different excitations: (a)_EESG, (b)_ARC-PMSG with SCL, (c)_ARC-PMSG with ACL.

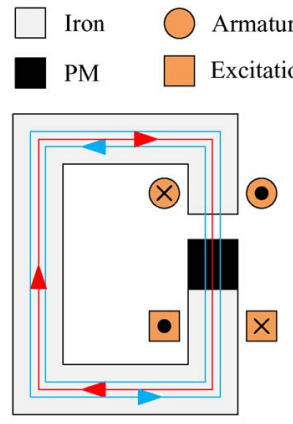

(a)

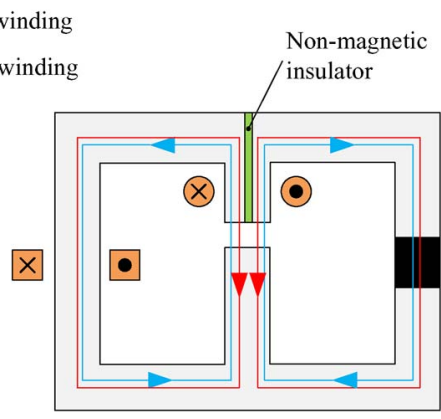

(b)
Fig. 5. Operation principles of HESMs: (a)—series HESMs; (b)—parallel HESMs. The red line represents the armature reaction, the solid blue line corresponds to the PM flux, and the dashed blue line refers to the flux produced by the excitation winding or compensating winding in the case of the ARCPMSG.

it is evident that series HESMs suit better for applications where the d-axis demagnetizing armature reaction is high. The armature reaction in this topology has to travel through the PM material, which results in a low inductance and a low armature reaction. The excitation current in the rotor is needed only to compensate for the armature reaction and not to significantly control the air gap flux density. Moreover, it is much easier to keep the air gap flux density nearly constant with a series HESM rather than with a parallel HESM. Consequently, the series excitation should work perfectly in island operation and cannot be regarded as a drawback.

The operation principle of the proposed topologies depicted in Fig. 4(b) and (c) in a simplified form is illustrated in Fig. 5(a). The main idea of the operation principle is that the main flux is first produced by the PMs, and the field winding coil is needed only to compensate the armature reaction to keep the air gap flux density approximately constant by adjusting the excitation current. Thus, instead of excitation winding, the rotor winding could be called compensating winding, and the whole 
machine an armature-reaction-compensated permanent magnet synchronous generator (ARC-PMSG). In the proposed structures, see Fig. 4(b) and (c), each pole pair has both excitation sources, and it is, therefore, possible to evenly compensate the stator armature reaction. The proposed topologies employ the same identical laminated stator iron core as for the EESG and utilize the same materials used in the conventional EESG.

The structure illustrated in Fig. 4(b) has four pairs of both PM and electrically excited poles. In such a construction, the PMs and excitation coils are located in every pole, and the flux produced by the electrical excitation passes through the PMs. Since the current linkages are connected in series, the machine in this paper will be called an ARC-PMSG with series current linkages (SCL). The PMs are embedded in the pole shoe leaving some space for the iron bridges.

The ARC-PMSG shown in Fig. 4(c) has four PM poles with the same polarity and four electrically excited poles again with the same but opposite polarity. When the rotor is rotated, a phase of the stator winding alternatively sees the current linkages of the PMs or the field windings. Therefore, this topology can be described as the ARC-PMSG with alternated current linkages (ACL). There are two PMs embedded in a V position in each of the PM poles.

\section{FEA}

To estimate the operation of the EESG and proposed ARCPMSGs, three simulated tests (no-load, on-load, and short circuit) were performed applying the Flux-2D software package by Cedrat Ltd. All the calculations were performed using a 2-D time stepping FEA.

\section{A. No-Load}

The no-load flux lines of the designed SGs shown in Fig. 6 verify the operation principle of the proposed ARC-PMSGs, that is the flux due to the excitation winding passes through the PMs. The air gap flux density distributions along one pole pitch of the SGs are presented in Fig. 7.

As it can be seen in Fig. 7(a), the magnitude of the air gap flux density in the ARC-PMSG with ACL across the PM pole is different from the magnitude of the air gap flux density across the electrically excited pole, which is due to the special rotor structure of this machine. Observing Fig. 7(b), we can see that the ARC-PMSG with the SCL and the EESG have the same behavior of the air gap flux densities: the magnitudes are equal under different poles.

According to Faraday's law, the voltages induced in the conductors under different poles will have different values in the ARC-PMSG with ACL because it has different air gap flux densities under different poles. This effect causes some limitations in the winding arrangement of the machine. Considering parallel paths $a$ of the stator winding, the winding of the ARCPMSG with $a=8$ will have unbalanced parallel paths, that is, the voltages induced in the parallel paths will be different. This in turn produces circulating currents in the winding, and as a result, unnecessary copper losses. However, the winding with $a=4$ gives balanced parallel paths. Therefore, the maximum

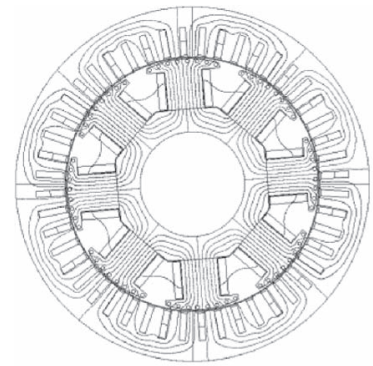

(a)

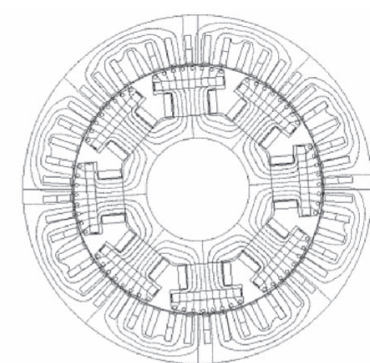

(b)

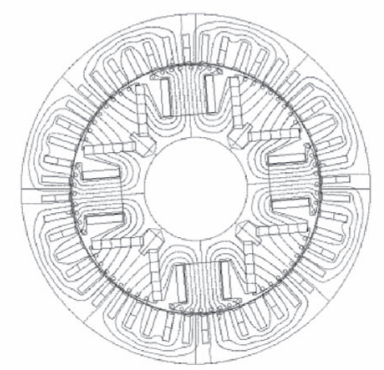

(c)

Fig. 6. No-load flux lines of the designed SGs: (a)_EESG, (b)_-ARC-PMSG with SCL, (c)-ARC-PMSG with ACL.

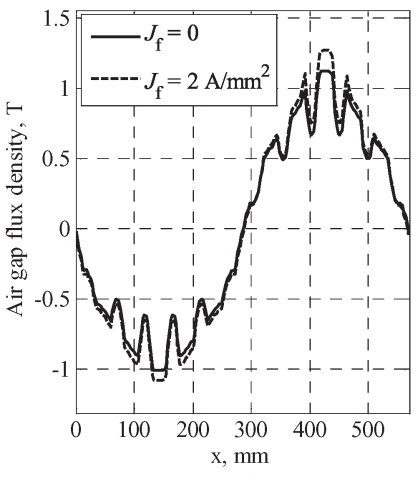

(a)

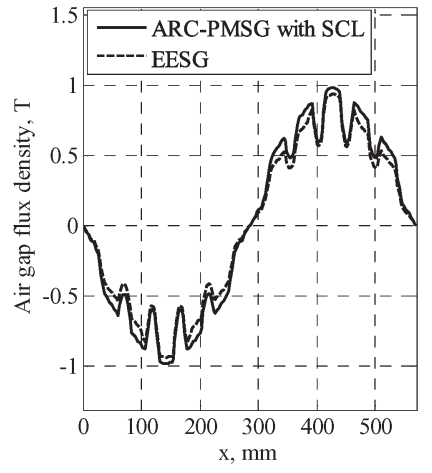

(b)
Fig. 7. Air gap flux density distributions: (a)—ARC-PMSG with ACL, where $J_{f}$ is the field winding current density; (b) - ARC-PMSG with SCL and EESG.

allowable number of parallel paths for the ARC-PMSG with ACL is $a=p$. In the case of the EESG and the ARC-PMSG with SCL, there are no limitations in the winding arrangement because of the symmetrical air gap flux densities.

According to the boundary conditions, the generator voltage must be kept between $\pm 10 \%$ in all normal cases. Thus, all the machines are designed so that the no-load induced phase voltage is equal to $1.1 \mathrm{p}$.u and the field winding current is equal to zero in the ARC-PMSGs at no-load.

\section{B. On-Load}

In this test, the generator is rotated at the nominal speed, and it supplies the load at three different power factors: $\cos \varphi=$ $0.9_{\text {cap }}, \cos \varphi=1$ and $\cos \varphi=0.8_{\text {ind }}$. The active-capacitive and pure resistive loads are studied to observe the terminal voltage of the SGs, while the active-inductive load is used to calculate the efficiencies of the SGs at nominal power, that is, $400 \mathrm{~kW}$. 


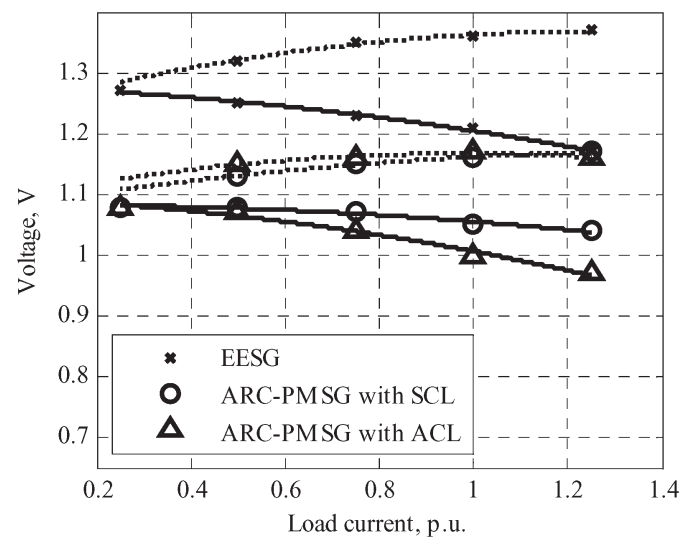

Fig. 8. Terminal voltage as a function of load current, $U_{s}=f\left(I_{s}\right)$ at $i_{f}=$ const, $\cos \varphi=$ const, and $f=f_{n}$. The dotted lines refer to $\cos \varphi=0.9_{\text {cap }}$ and the solid ones correspond to $\cos \varphi=1$. The excitation current of the EESG is the nominal value, while the proposed HESGs have a zero excitation current.

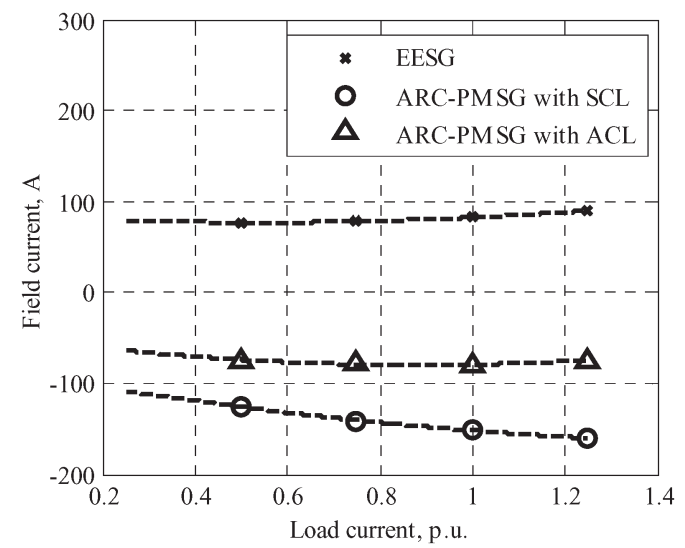

Fig. 9. Excitation current as a function of load current, $i_{f}=f\left(I_{s}\right)$ at $U_{s}=$ 1 p.u., $\cos \varphi=0.9_{\text {cap }}$, and $f_{n}=$ const.

Fig. 8 provides the curves of the terminal voltages of the SGs as a function of load current when the excitation current of the EESG is equal to its nominal value and the proposed ARCPMSGs work without electrical excitation, that is, $U_{s}=f\left(I_{s}\right)$ at $i_{f}=$ const, $\cos \varphi=$ const, and $f=f_{n}$. According to these curves, the voltages of the SGs at $\cos \varphi=0.9_{\text {cap }}$ are more than the allowed maximum value, in other words, $110 \%$ of the rated voltage. This is because of the magnetizing armature reaction. To get the allowed terminal voltage, the excitation current must be decreased. Fig. 9 demonstrates how the excitation current must be changed to get the rated voltage, that is, $i_{f}=f\left(I_{s}\right)$ at $U_{s}=1$ p.u., $\cos \varphi=0.9_{\text {cap }}$, and $f_{n}=$ const. At a pure resistive load, the voltages of the ARC-PMSGs are within the allowed range, that is, $\pm 10 \%$ of the rated value, whereas the terminal voltage of the EESG at the rated excitation current is above 1.1 p.u., see Fig. 8 .

In general, the machine efficiency is a ratio of the output to input powers, where the last term is a sum of the output power and the total losses. The total losses of an SG include mechanical losses, stator and rotor copper (or Joule) losses, stator iron losses, and additional losses. The losses of the proposed ARC-PMSGs can also contain PM losses. The efficiencies, loss distributions, and power densities in the rated point of different SGs are presented in Table IV.
TABLE IV

EFFiciencies, Loss Distributions, AND Power Densities of StUdied SGs at Rated OPERATING Point

\begin{tabular}{lccc}
\hline \hline Parameter & EESG & $\begin{array}{c}\text { ARC- } \\
\text { PMSG } \\
\text { with SCL }\end{array}$ & $\begin{array}{c}\text { ARC- } \\
\text { PMSG } \\
\text { with ACL }\end{array}$ \\
\hline Mechanical losses, kW & 6.4 & 6.2 & 6 \\
Stator iron losses, kW & 3.9 & 4.3 & 4.6 \\
PM losses, kW & 0 & $4 \cdot 10^{-3}$ & $4 \cdot 10^{-3}$ \\
Stator copper losses, kW & 2.5 & 2.5 & 2.4 \\
Rotor copper losses, kW & 10.3 & 3.40 & 3.1 \\
Rotor pole shoe losses, kW & 2 & 2 & 2 \\
Additional losses, kW & 2 & 2 & 2 \\
Output power, kW & 400 & 400 & 400 \\
Efficiency, \% & 93.7 & 95.2 & 95.2 \\
Power density, W/kg & 165 & 173 & 180 \\
\hline \hline
\end{tabular}

The mechanical losses of the horizontal-shaft salient pole generator can be expressed according to [23] as

$$
P_{\text {mech }}=1.83 \cdot 2 p \sqrt{l_{1}}\left(\frac{v}{40}\right)^{3} .
$$

The stator iron losses and PM losses are estimated by the FEA. According to [24], the eddy current losses in PMs are calculated as the active power dissipated in these regions considering the magnets as solid conductors. The losses in electrical sheets are computed by the tool termed as Loss Surface Model (LSM) which is integrated in the FEM software FLUX.

The calculation of the additional losses includes the calculations of the additional losses both in the no-load and on-load operation. The additional losses at no load can be determined as in [21]

$$
\begin{aligned}
P_{\text {add }, \mathrm{nl}}=0.5 \cdot 2 p \alpha_{\mathrm{p}} & \tau_{\mathrm{p}} l_{1} k_{0}\left(\frac{Q_{s} n}{10^{4}}\right)^{1.5} \\
& \times\left(B_{1 \delta}\left(k_{\mathrm{C} 1}-1\right) \tau_{\mathrm{us}} \cdot 10^{3}\right)^{2} \cdot 10^{-3}
\end{aligned}
$$

where $\alpha_{\mathrm{p}}$ is the relative pole width, $\tau_{\mathrm{p}}$ is the stator pole pitch, $\tau_{\text {us }}$ is the stator slot pitch, $k_{0}$ is equal to $4.6,8.6$, and 23.3 for the $1 \mathrm{~mm}$ and $2 \mathrm{~mm}$ core sheet thicknesses of the rotor pole and solid pole shoes, respectively, $B_{1 \delta}$ is the fundamental harmonic of the air flux density and $k_{\mathrm{C} 1}$ is the Carter factor for the stator slots assuming a smooth rotor.

The additional losses of the designed SGs in on-load operation are assumed to be $0.5 \%$ of the generator output power $P_{n}$.

As can be seen in Table IV, the PM losses can be neglected. In actual machines, there should be no significant PM losses because the PMs are buried quite deep. Moreover, because of the presence of the damper winding and the rotor lamination, the flux produced by the high harmonics should not penetrate deep enough.

Table IV demonstrates that the efficiencies of the ARCPMSGs in comparison with the EESG are higher by $1.5 \%$ mainly because of the rotor copper losses. Other losses of the SGs are almost the same.

According to the calculated results, the efficiencies and power densities of the ARC-PMSGs are higher compared with the EESG. 
TABLE V

RESUlts OF THE FEA SHORT-CIRCUIT TEST

\begin{tabular}{|c|c|c|c|}
\hline Parameter & EESG & $\begin{array}{c}\text { ARC- } \\
\text { PMSG } \\
\text { with SCL }\end{array}$ & $\begin{array}{c}\text { ARC- } \\
\text { PMSG } \\
\text { with ACL }\end{array}$ \\
\hline Induced phase voltage, $E_{0}$ & $347 \mathrm{~V}$ & $310 \mathrm{~V}$ & $308 \mathrm{~V}$ \\
\hline $\begin{array}{l}\text { Sustained short-circuit } \\
\text { current, } I_{\mathrm{sc}}\end{array}$ & $2040 \mathrm{~A}$ & $2880 \mathrm{~A}$ & $2190 \mathrm{~A}$ \\
\hline Field current linkage, $\Theta_{\mathrm{f}}$ & $\begin{array}{c}9970 \\
\text { A/pole }\end{array}$ & $\begin{array}{c}3360 \\
\text { A/pole }\end{array}$ & $\begin{array}{c}5480 \\
\text { A/pole }\end{array}$ \\
\hline Current ratio, $I_{\mathrm{sc}} / I_{\mathrm{s}}$ & 3 & 4.5 & 3.4 \\
\hline
\end{tabular}

TABLE VI

ACTIVE MASS COMPARISON

\begin{tabular}{lccc}
\hline \hline Masses & EESG & $\begin{array}{c}\text { ARC- } \\
\text { PMSG } \\
\text { with SCL }\end{array}$ & $\begin{array}{c}\text { ARC- } \\
\text { PMSG } \\
\text { with ACL }\end{array}$ \\
\hline PM, kg & 0 & 145 & 100 \\
Rotor iron, kg & 850 & 770 & 795 \\
Stator iron, kg & 1000 & 920 & 875 \\
Rotor copper, kg & 205 & 120 & 95 \\
Stator copper, kg & 375 & 360 & 355 \\
Total mass, kg & 2430 & 2315 & 2220 \\
\hline \hline
\end{tabular}

\section{Short Circuit}

The short-circuit test by the FEA is performed to check whether the short-circuit requirement mentioned in the boundary conditions is met: the sustained short-circuit current must be three times the rated current. The results of the short-circuit tests of the SGs are presented in Table V. All three SGs can meet the short-circuit requirement.

It should be noted here that the ARC-PMSGs can fulfill the short-circuit demand at rated field winding current, while the EESG needs to increase the excitation current by 1.5 times the rated value. Usually, during a short circuit, the extra field winding current in the conventional EESG is supplied for example by excitation generators having a large voltage reserve for the short circuit excitation. In brushed EESGs, suitable current transformers are often used to supply extra current to the field winding during a short circuit. With the ARC-PMSGs, such arrangements could be simplified. This fact gives an additional advantage to the ARC-PMSGs in comparison with the EESG.

\section{Comparison of SGs With Different Excitations}

The results of the FEA showed that all three studied SGs can meet the boundary conditions. However, the ARC-PMSGs demonstrated better results than the EESG. In no-load, the proposed ARC-PMSGs work without electrical excitation.

Table VI provides a comparison of the active masses of the EESG and two ARC-PMSGs. As can be seen in Table VI, the total mass of the ARC-PMSG with ACL is by $8 \%$ lower than that of the EESG. Additionally, the ARC-PMSG with ACL has the lowest mass of the PM material which is the most expensive component in an electrical machine.

Despite the expensive PMs of the ARC-PMSGs which result in a higher price compare to the price of the EESG, the economic study presented in [19] shows that the electricity price of the ARC-PMSGs will be a bit lower. Moreover, the simplified payback period of the ARC-PMSGs is one year for the ARC-

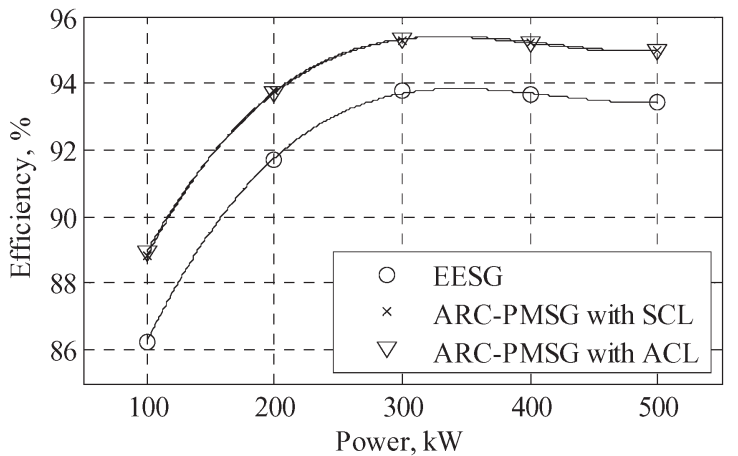

Fig. 10. Efficiency curves of the studied SGs. The efficiency curves of the ARC-PMSGs are on top of each other because they are identical in practice.

PMSG with ACL and two years for the ARC-PMSG with SCL. Thus, from the economical point of view, the proposed ARCPMSGs could be also competitive with the conventional EESG.

Fig. 10 provides efficiency curves of the studied SGs. The efficiency curves are built based on the results of the on-load test, that is, all the SGs supply inductive loads with a load power factor $\cos \varphi=0.8_{\text {ind }}$ at different load currents. As can be seen in Fig. 10, the efficiencies of the ARC-PMSGs are evidently higher than that of the EESG. Usually, the electrical machines do not work at full load; in practice, the working points lie in the range of $60 \%-100 \%$ of the load. Therefore, the maximum efficiencies should be placed in the middle of this working region as shown in Fig. 10. The maximum values of the efficiencies of the conventional EESG and ARC-PMSGs are $93.8 \%$ and $95.3 \%$, respectively.

Summarizing the above results and analyses, it is evident that the ARC-PMSGs showed better performance than the EESG both from the technical and economic point of views. However, the ARC-PMSG with ACL demonstrated the following results better than the ARC-PMSG with SCL:

1) high power density;

2) low mass of the expensive rare-earth PM material;

3) low total mass and

4) short simplified payback period.

Therefore, it was decided to study an ARC-PMSG with ACL further.

\section{EXPERIMENTAL Results}

To verify the operation principle of the proposed ARCPMSG and fulfillment of the boundary conditions, the test machine was built. Based on the above results and analyses, it was decided to construct an ARC-PMSG with ACL and $55 \mathrm{~kW}$ power. The stator of the test machine originally belongs to an induction motor, see Fig. 11. The stator of the test machine employs the three-phase full-pitched single-layer winding with three slots per pole and phase. The design specifications and the main geometry data of the test machine are given in Tables VII and VIII, respectively.

The assembled rotor of the ARC-PMSG with ACL shown in Fig. 12 contains 5 damper bars per pole. The end ring of the damper bars are replaced with the copper plates. To observe the temperature in the PM, two thermal sensors Pt 100 were 


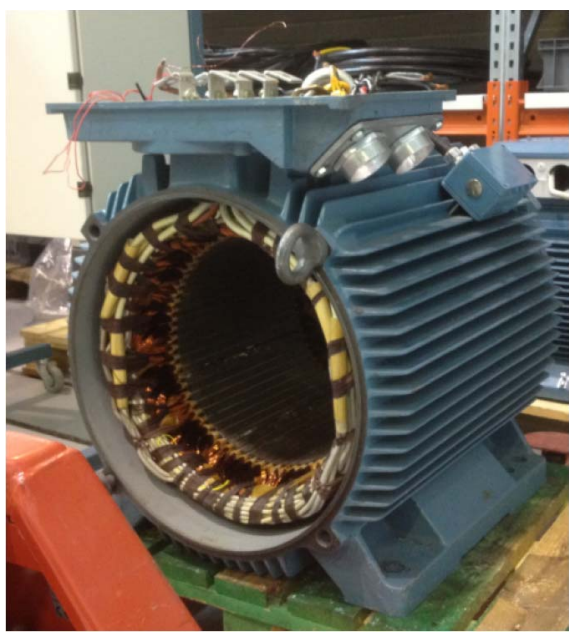

Fig. 11. Stator of the test machine which originally belongs to the induction machine with the power of $55 \mathrm{~kW}$.

TABLE VII

Design SPECIFICATIONS OF THE PRototype

\begin{tabular}{lcc}
\hline \hline Parameter & Value & Unit \\
\hline Number of phases, $m$ & 3 & - \\
Nominal rotational speed, $n$ & 750 & $\mathrm{rpm}$ \\
Nominal power, $S_{\mathrm{n}}$ & 69 & $\mathrm{kVA}$ \\
Nominal line-to-line voltage, $U_{\mathrm{n}}$ & 660 & $\mathrm{~V}$ \\
Nominal phase current, $I_{\mathrm{n}}$ & 60 & $\mathrm{~A}$ \\
Power factor, cos $\varphi$ & $0.8_{\text {ind }}$ & - \\
Number of pole pairs, $p$ & 4 & - \\
Frequency, $f$ & 50 & $\mathrm{~Hz}$ \\
\hline \hline
\end{tabular}

TABLE VIII

MAin Geometry DAta of The Prototype

\begin{tabular}{lcc}
\hline \hline Parameter & Value & Unit \\
\hline Air gap diameter, $D_{\mathrm{s}}$ & 330 & $\mathrm{~mm}$ \\
Length, $l$ & 310 & $\mathrm{~mm}$ \\
Air gap length in the pole centre, $\delta$ & 1.5 & $\mathrm{~mm}$ \\
Slots number, $Q_{\mathrm{s}}$ & 72 & - \\
Phase turns number, $N_{\mathrm{ph}}$ & 81 & - \\
Number of PMs per pole & 2 & - \\
Number of excitation field turns per pole, $N_{\mathrm{f}}$ & 90 & - \\
Number of parallel paths, $a$ & 4 & - \\
\hline \hline
\end{tabular}

installed between the PM and the rotor yoke, see Fig. 13. The cables that connect the Pt100 with a transmitter go in the shaft before the end shield bearing. The transmitter is installed at the edge of the shaft whereas the receiver box is mounted on the end cap that covers the external fan, see Fig. 14. Inside the receiver box, there is an IC chip FT245RL, which communicates with a $\mathrm{PC}$ over USB. The temperature of the surrounding medium was $25{ }^{\circ} \mathrm{C}$.

In the laboratory tests, the rotor of the generator was driven by a dc motor through a torque transducer connected at the shaft of the machine. The power of the dc motor is $180 \mathrm{~kW}$. Since the dc motor has limited rotational speed, it was decided to design the test machine with the frequency of $50 \mathrm{~Hz}$. The excitation current of the machine was supplied from the dc stationary supply which is controlled manually, see Fig. 14. The current

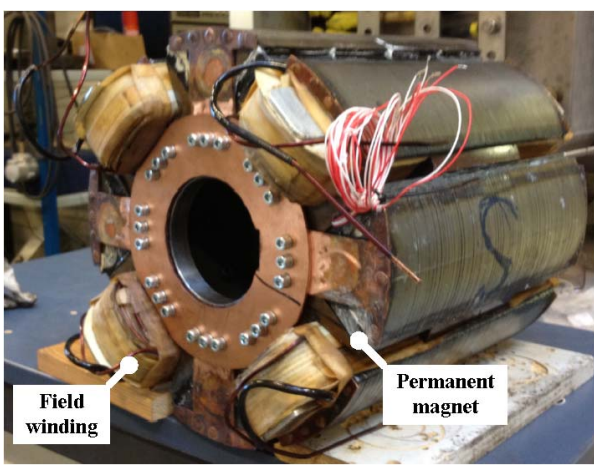

Fig. 12. Assembled rotor of the ARC-PMSG with ACL.

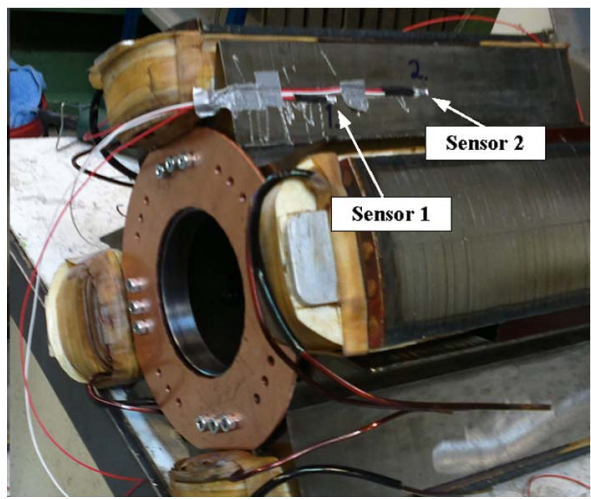

Fig. 13. Arrangement of the thermal sensors installed in the rotor side to measure the temperature in the PM.

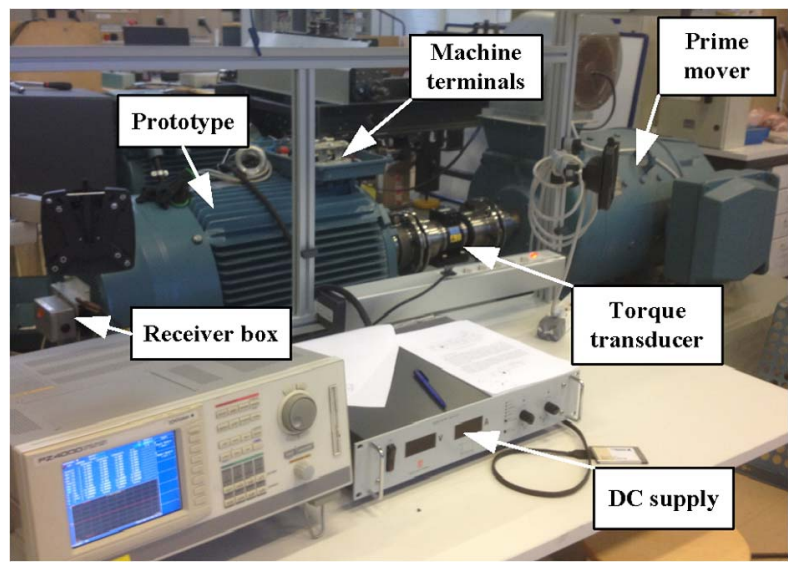

Fig. 14. Laboratory test setup: a dc machine with a power of $180 \mathrm{~kW}$ acts as a prime mover at no-load, on-load, and short circuit.

and voltage measurements were performed at the terminals of the machine.

Fig. 15 presents no-load PM-induced voltage distributions in three phases. The measured RMS value of the PM-induced phase voltage is $402 \mathrm{~V}$, whereas the calculated RMS value is $419 \mathrm{~V}$ (or 1.1 p.u.) which gives a $4 \%$ difference. This difference can be explained partly by the fact that the effective length of the PM rotor is less than the real length of the machine because of the end effects. This issue has been studied for instance in [25]. To increase the rotor effective length, the rotor length should be made longer than the stator length. Another explanation is based on the inaccuracy of the manufacturing 


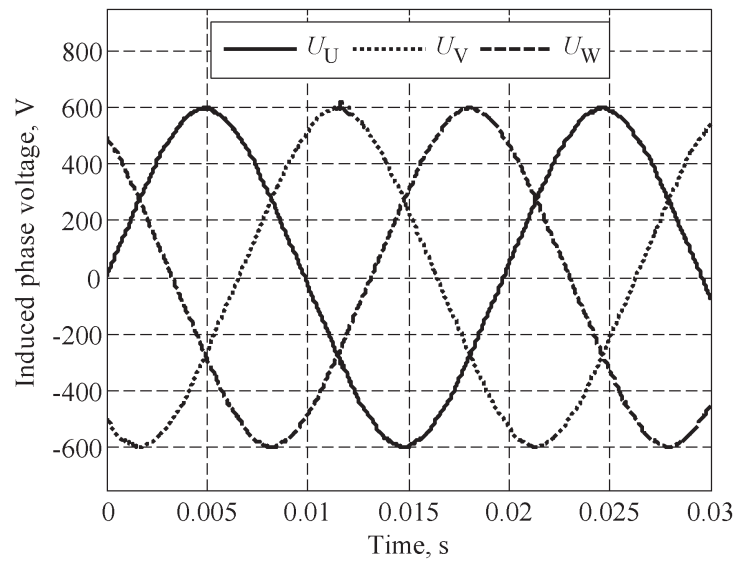

Fig. 15. Measured no-load PM-induced phase voltage waveform distributions. The RMS value is $402 \mathrm{~V}$.

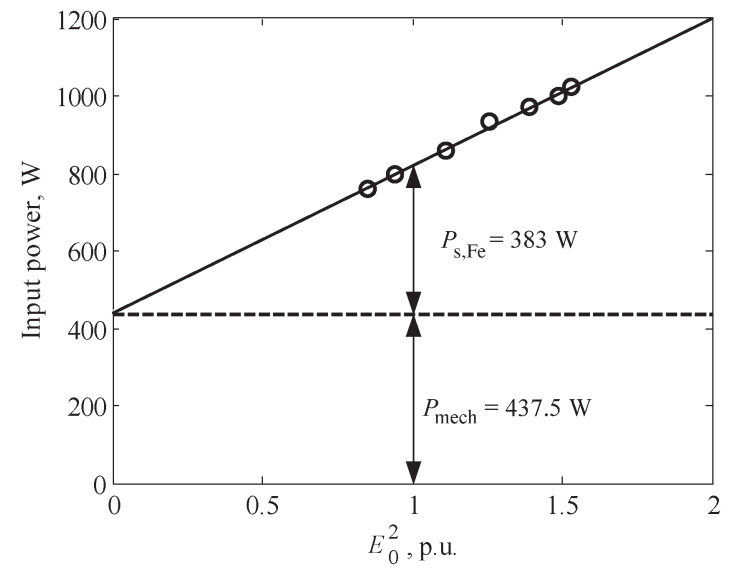

Fig. 16. Input power as a function of the squared open-circuit voltage at the rated speed.

of the rotor poles or a slight variation in the PM material properties.

In general, the voltage waveform distributions of SGs should be close to a sinusoidal one. The fulfillment of this requirement can be estimated for example by an index term called the total harmonic distortion (THD), which can be expressed as

$$
\mathrm{THD}=\frac{100}{U_{1}} \sqrt{\sum_{\nu=2}^{\infty} U_{\nu}^{2}}
$$

where $U_{1}$ is the RMS or peak voltage of the fundamental harmonic and $U_{\nu}$ is the RMS or peak voltage of the $\nu$ th harmonic. Based on the experimental results, the THD of the no-load PM-induced phase voltage is 3\%, which demonstrates almost a sinusoidal waveform.

Fig. 16 presents the results of the losses segregation at noload operation. By measuring the input power $P_{\text {ino }}$ for each open-circuit voltage, it is possible to determine the iron and mechanical losses. As the speed is kept constant, the mechanical losses are constant, that is $P_{\text {mech }}=$ const. Only the iron losses $P_{\mathrm{s}, \mathrm{Fe}}$ increase approximately with voltage squared.

The results of the 2-D FEA obtained by the LSM give $532 \mathrm{~W}$, which are overestimated by $40 \%$ compared to the experimental ones. The analytical calculation based on (9) which is
TABLE IX

EXPERIMENTAL RESULTS OF THE ON-LOAD TESTS

\begin{tabular}{ccccccc}
\hline \hline$I_{\mathrm{f}}, \mathrm{A}$ & $U_{\mathrm{ph}}, \mathrm{V}$ & $I_{\mathrm{s}}, \mathrm{A}$ & $P_{\text {out }}, \mathrm{kW}$ & $\cos \varphi$ & $\eta, \%$ & $S_{\text {out }} / S_{\mathrm{n}}$ \\
\hline 8.8 & 380.2 & 29.8 & 27.2 & $0.8_{\text {ind }}$ & 95.6 & 0.50 \\
9.9 & 380.8 & 31.1 & 28.4 & $0.8_{\text {ind }}$ & 95.5 & 0.52 \\
10.3 & 380.6 & 36.2 & 41.3 & $0.8_{\text {ind }}$ & 96.1 & 0.60 \\
25.2 & 375.1 & 57.5 & 51.8 & $0.8_{\text {ind }}$ & 94.9 & 0.94 \\
\hline \hline
\end{tabular}

TABLE $X$

Results of the Sudden Three-Phase Short-Circuit Test

\begin{tabular}{lcc}
\hline \hline \multicolumn{1}{c}{ Parameter } & Value & Unit \\
\hline Induced phase voltage, $E_{0}$ & 460 & $\mathrm{~V}$ \\
Sustainable short-circuit current, $I_{\mathrm{sc}}$ & 181 & $\mathrm{~A}$ \\
Currents ratio, $I_{\mathrm{sc}} / I_{\mathrm{s}}$ & 3 & p.u. \\
\hline \hline
\end{tabular}

usually used for the traditional SGs results in $270 \mathrm{~W}$ which are lower than the experimental result. The difference between the calculated and experimentally determined mechanical losses is also about $40 \%$, which can be explained partly by the special structure of the test machine. Another reason lies in the fact that the rotor of the test machine was not balanced.

In the on-load tests, the load of the generator represents resistors with different values connected in parallel with an induction machine which was working at no-load. The load power factor was fixed at $\cos \varphi=0.8_{\text {ind }}$. The experimental results of the ARC-PMSG with ACL at on-load are shown in Table IX.

The results of the no-load and on-load tests verify the operation principle of the ARC-PMSG with ACL: the main flux is first produced by the PMs, and the excitation coils are only needed to compensate the armature reaction to keep the terminal voltage constant when the generator is loaded.

Table $\mathrm{X}$ demonstrates the results of the sudden three-phase short-circuit test. According to these results, the ARC-PMSG with ACL can provide the sustainable short-circuit current which is three times the rated one.

The temperature sensors Pt 100 at $94 \%$ of the rated load showed about $50{ }^{\circ} \mathrm{C}$ and during the short circuit tests the temperature was increased up to $68{ }^{\circ} \mathrm{C}$. The results of the thermal sensors showed that the temperature in the PMs is within the allowable limits.

\section{CONCLUSION}

This paper dealt with the feasibility and prototyping of an ARC-PMSG in island operation.

The analyses based on the phasor diagram showed that a pure PMSG for island operation is overdimensioned and hence economically inefficient. Therefore, a direct-on-line PMSG is not suitable for island operation.

The designed conventional EESG and two proposed ARCPMSGs for island operation were presented. The operation principle of the proposed ARC-PMSGs was discussed.

The study and comparison of the conventional EESG and proposed ARC-PMSGs were done with the help of the 2-D FEA. The results of the study showed that all three studied 
SGs can meet the main boundary conditions. However, from the efficiency point of view, the proposed ARC-PMSGs performed better than the conventional EESG. This demonstrates that an ARC-PMSG has some potential to be an alternative solution for island operation.

Among the two proposed ARC-PMSGs, the ARC-PMSG with ACL demonstrated better results than the ARC-PMSG with SCL. Therefore, the test machine of this topology was decided to build and test it.

The experimental results of the test machine verified the operation principle of the ARC-PMSG: the main flux is first produced by the PMs, and the excitation coil is only needed to compensate the armature reaction. The short-circuit tests demonstrated that the proposed ARC-PMSG with ACL can fulfill the short-circuit demand, that is, the sustainable shortcircuit current is three times the rated current for at least two seconds, which is one of the most challenging requirements for a pure direct-on-line PMSG.

\section{ACKNOWLEDGMENT}

The authors would like to thank LUT DPEEE FiDiPro and Academia of Finland for their support.

\section{REFERENCES}

[1] N. Patin, L. Vido, E. Monmasson, J.-P. Louis, M. Gabsi, and M. Lecrivain, "Control of a hybrid excitation synchronous generator for aircraft applications," IEEE Trans. Ind. Electron., vol. 55, no. 10, pp. 3772-3783, Oct. 2008.

[2] Y. Amara, L. Vido, M. Gabsi, E. Hoang, A. Hamid Ben Ahmed, and M. Lecrivain, "Hybrid excitation synchronous machines: Energy-efficient solution for vehicles propulsion," IEEE Trans. Veh. Technol., vol. 58, no. 5, pp. 2137-2149, Jun. 2009.

[3] T. Kosaka, M. Sridharbabu, M. Yamamoto, and N. Matsui, "Design studies on hybrid excitation motor for main spindle drive in machine tools," IEEE Trans. Ind. Electron., vol. 57, no. 11, pp. 3807-3813, Nov. 2010.

[4] Q. Zhang, S. Huang, and G. Xie, "Design and experimental verification of hybrid excitation machine with isolated magnetic paths," IEEE Trans. Energy Convers., vol. 25, no. 4, pp. 993-1000, Dec. 2010.

[5] M. Shi, B. Zhou, J. Wei, Z. Zhang, Y. Mao, and C. Han, "Design and practical implementation of a novel variable-speed generation system," IEEE Trans. Ind. Electron., vol. 58, no. 11, pp. 5032-5040, Nov. 2011.

[6] A. Ammar, A. C. Berbecea, F. Gillon, and P. Brochet, "Influence of the ratio of hybridization on the performances of synchronous generator with hybrid excitation," in Proc. IEEE ICEM, Sep. 2012, pp. 2921-2926.

[7] D. Hagstedt, A. Reinap, J. Ottosson, and M. Alaküla, "Design and experimental evaluation of a compact hybrid excitation claw-pole rotor," in Proc. IEEE ICEM, Sep. 2012, pp. 2896-2901.

[8] D. Fodorean, A. Djerdir, I.-A. Viorel, and A. Miraoui, "A double excited synchronous machine for direct drive application-Design and prototype tests," IEEE Trans. Energy Convers., vol. 22, no. 3, pp. 656-665, Sep. 2007.

[9] H. Bali, Y. Amara, G. Barakat, R. Ibtiouen, and M. Gabsi, "Analytical modeling of open circuit magnetic field in wound field and series double excitation synchronous machines," IEEE Trans. Magn., vol. 46, no. 10, pp. 3802-3815, Oct. 2010.

[10] B. Nedjar, S. Hlioui, M. Lécrivain, Y. Amara, L. Vido, and M. Gabsi, "Study of a new hybrid excitation synchronous machine," in Proc. IEEE ICEM, Sep. 2012, pp. 2927-2932.

[11] Y. Amara, S. Hlioui, R. Belfkira, G. Barakat, and M. Gabsi, "Comparison of open circuit flux control capability of a series double excitation machine and a parallel double excitation machine," IEEE Trans. Veh. Technol., vol. 60, no. 9, pp. 4194-4207, Nov. 2011.

[12] Z. Zhang, Y. Tao, and Y. Yan, "Investigation of a new topology of hybrid excitation doubly salient brushless DC generator," IEEE Trans. Ind. Electron., vol. 59, no. 6, pp. 2550-2556, Jun. 2012.

[13] T. Hosoi, H. Watanabe, K. Shima, T. Fukami, R. Hanaoka, and S. Takata, "Demagnetization analysis of additional permanent magnets in salient-pole synchronous machines with damper bars under sudden short circuits," IEEE Trans. Ind. Electron., vol. 59, no. 6, pp. 2448-2456, Jun. 2012

[14] K. Yamazaki, K. Nishioka, K. Shima, T. Fukami, and K. Shirai, "Estimation of assist effects by additional permanent magnets in salientpole synchronous generators," IEEE Trans. Ind. Electron., vol. 59, no. 6, pp. 2515-2523, Jun. 2012

[15] K. Kamiev, J. Nerg, J. Pyrhönen, and V. Zaboin, "Hybrid excitation synchronous generators for island operation," in Proc. IEEE ICEM, 2010, pp. 1-6.

[16] J. F. Gieras, "PM synchronous generators with hybrid excitation systems and voltage control capabilities: A review," in Proc. IEEE ICEM, 2012, pp. 2573-2579.

[17] Y. Wang and Z. Deng, "Hybrid excitation topologies and control strategies of stator permanent magnet machines for DC power system," IEEE Trans. Ind. Electron., vol. 59, no. 12, pp. 4601-4616, Dec. 2012.

[18] K. Kamiev, J. Nerg, J. Pyrhönen, V. Zaboin, V. Hrabovcová, and P. Rafajdus, "Hybrid excitation synchronous generators for island operation," IET Electr. Power Appl., vol. 6, no. 1, pp. 1-11, Jan. 2012.

[19] K. Kamiev, J. Nerg, J. Pyrhönen, V. Zaboin, and J. Tapia, "Feasibility of different excitation methods of synchronous generators in island operation," in Proc. IEEE ICEM, Sep. 2012, pp. 2902-2908.

[20] R. Moncada, J. Tapia, and T. Jahns, "Inverse-saliency PM motor performance under vector control operation," in Proc. IEEE ECCE, Sep. 2009, pp. 2368-2373.

[21] I. P. Kopylov, (in Russian), Design of Electrical Machines, 4th ed. Moscow, Russia: Vysshaya Shkola, 2005.

[22] J. Pyrhönen, T. Jokinen, and V. Hrabovcova, Design of Rotating Electrical Machines. Hoboken, NJ, USA: Wiley, 512 pages.

[23] V. T. Kasyanov, Design of Salient-Pole Synchronous Machines, St. Petersburg, Russia: N.G. Kuznetsov Naval Academy, 1951.

[24] G. Ugalde, G. Almandoz, J. Poza, and A. Gonzalez, "Computation of iron losses in permanent magnet machines by multi-domain simulations," in Proc. 13th EPE, 2009, pp. 1-10.

[25] J. Pyrhönen, V. Ruuskanen, J. Nerg, J. Puranen, and H. Jussila, "Permanent-magnet length effects in AC machines," IEEE Trans. Magn., vol. 46 , no. 10 , pp. $3783-3789$, Oct. 2010.

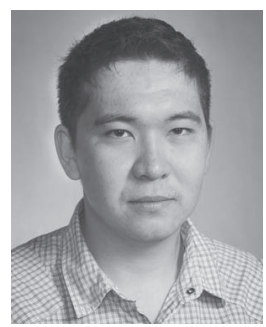

Katteden Kamiev received the B.Sc. and M.Sc. degrees in electrical engineering from Saint-Petersburg State Polytechnical University, Saint-Petersburg, Russia, in 2006 and 2008, respectively, and the M.Sc. degree in electrical engineering from Lappeenranta University of Technology (LUT), Lappeenranta, Finland, in 2008 (Double Degree Program), where he is currently working in the field of electrical machines as a postgraduate student.

His research interests are traditional synchronous machines, permanent-magnet synchronous machines, and hybrid excitation synchronous machines.

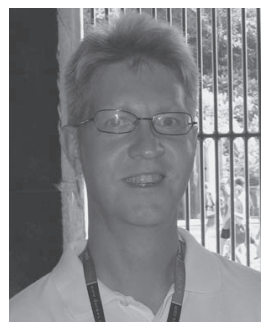

Janne Nerg (M'99-SM'12) received the M.Sc. degree in electrical engineering, the Licentiate of Science (Technology) degree, and the D.Sc. (Technology) degree from Lappeenranta University of Technology (LUT), Lappeenranta, Finland, in 1996, 1998 , and 2000, respectively.

$\mathrm{He}$ is currently an Associate Professor in the Department of Electrical Engineering at LUT. His research interests are in the field of electrical machines and drives, especially electromagnetic and thermal modeling and design of electromagnetic devices. 


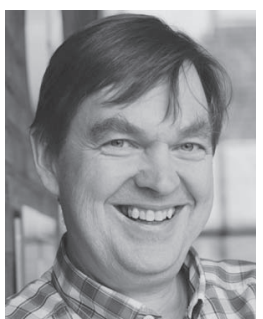

Juha Pyrhönen (M'06) received the D.Sc. (Tech.) degree from Lappeenranta University of Technology (LUT), Lappeenranta, Finland, in 1991.

He became an Associate Professor of Electrical Engineering at LUT in 1993 and Professor of Electrical Machines and Drives in 1997. He is currently Head of the Department of Electrical Engineering, LUT, where he is engaged in research and development of electric motors and electric drives. His current research interests include synchronous machines and drives, induction motors and drives, and solidrotor high-speed induction machines and drives.

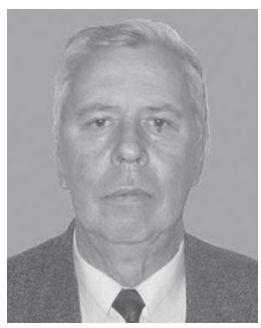

Valeriy Zaboin received the Ph.D. and Doctor of Engineering degrees from Saint-Petersburg State Polytechnical University, Saint-Petersburg, Russia, in 1978 and 2002, respectively.

He became an Associate Professor in 1982 and Professor of Electrical Machines in 1995. He is currently Head of the Department of Electrical Machines, Saint-Petersburg State Polytechnical University, where he is involved in the calculation, design, and mathematical modeling of electrical machines.

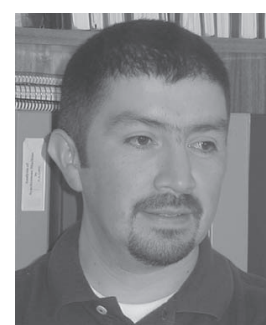

Juan Tapia (M'00) received the B.Sc. and M.Sc. degrees in electrical engineering from the University of Concepcion, Concepcion, Chile, in 1991 and 1997, respectively and the $\mathrm{Ph} . \mathrm{D}$. degree from the University of Wisconsin, Madison, WI USA, in 2002.

Since 1992, he has been with the Department of Electrical Engineering, University of Concepcion, where he is currently an Associate Professor. Since 2010, he has been a FiDiPro Fellow of the Academy of Finland at Lappeenranta University of Technology, where he conducts research on PM machines as part of the LUT-Energia Group. His primary research areas are electrical machine design, numerical methods for electromagnetic field computation, DSP-based electric machine control, and renewable energy. 